\title{
DOAÇÃO DE ÓRGÃOS E TECIDOS PARA TRANSPLANTES: SOB A ÓTICA DOS ACADÊMICOS DE ENFERMAGEM
}

\author{
Organ and tissue donation for transplant: Under the view of the of nursing academics
}

\author{
Maísa Renata Hostim, Morgana Dacoregio, Rosilda Verissimo Silva
}

\begin{abstract}
RESUMO
No Brasil, tem crescido a necessidade de transplantes e o enfermeiro é responsável por várias ações nas diferentes etapas desse processo. Durante a formação, é relevante conhecer os aspectos nele envolvidos. Objetivo: Caracterizar o conhecimento dos acadêmicos de Enfermagem de um curso de graduação de Joinville/SC sobre doação de órgãos e tecidos para transplantes. Métodos: Pesquisa qualitativa, de caráter descritivo, realizada com 152 participantes matriculados do primeiro ao quinto ano do curso. Dados coletados por meio de questionários com questões abertas e fechadas respondidas a próprio punho no período de aulas. Procedeu-se à análise de conteúdo na modalidade de análise temática. Resultados: Da interpretação, surgiram as seguintes categorias: reflexão sobre o processo de doação de órgãos e tecidos para transplantes de modo favorável; o processo de doação de órgãos e tecidos como um ato solidário e avanço tecnológico capaz de salvar vidas; a articulação dos serviços informativos para o esclarecimento da população; a formação do enfermeiro como estratégia para ampliar o processo de transplante e doação. Conclusão: Observou-se que os acadêmicos possuem conhecimento sobre o tema, identificando a viabilidade dos órgãos, aqueles que podem ser transplantados e as doenças que restringem a doação, entre outras informações. No geral, considera-se necessária a abordagem do tema durante a formação. Pressupõe-se que os cursos possam desenvolver mecanismos educacionais para abordar o assunto.
\end{abstract}

Descritores: Morte Encefálica; Transplante de Órgãos; Obtenção de Tecidos e Órgãos; Enfermagem.

Instituição:

Departamento de Enfermagem - Faculdade LELUSC - Joinville/SC

\section{Correspondência:}

Nome: Maísa Renata Hostim

End.: Rua Princesa Isabel, 438 - Joinville/SC

Tel.: (47) 3026-8000

E-mail: maisahostim@hotmail.com

\section{INTRODUÇÃO}

Atualmente, muito tem se falado sobre doação de órgãos, pois é uma temática motivadora para diversas pessoas que estão na constante luta pela vida. Depender do órgão de outro indivíduo para viver é uma realidade extremamente exaustiva, mas, infelizmente, muitos vivenciam essa situação no Brasil e no mundo. A doação de órgãos e tecidos é considerada uma das únicas alternativas para aqueles que estão em busca da cura ou melhora no tratamento ${ }^{1}$ e na qualidade de vida.

Para ser doador, basta declarar-se em vida, e comunicar à família. Não é necessário realizar registros em documentos oficiais, pois estes perderam a validade, desde dezembro de 2000. ${ }^{2} \mathrm{Em} \mathrm{1997,} \mathrm{foi} \mathrm{promulgada} \mathrm{a}$ Lei $n^{\circ} 9.437^{3}$, que, com a Lei $n^{0} 10.211 / 200$, regula a doação de órgãos e tecidos no país. ${ }^{4}$ 
Embora o Brasil venha se desenvolvendo nesse campo há quase cinco décadas, somente a partir de 1997 o tema começou a ocupar destaque na saúde pública e passou a receber recursos financeiros para aprimorar a qualidade do processo. ${ }^{5} \mathrm{Em}$ Santa Catarina, a Central de Notificação, Captação, e Distribuição de Órgãos e Tecidos (CNCDO) foi criada com o Decreto Estadual $n^{\circ} 553$, de 21 de setembro de 1999. Essa Central tem como função coordenar as atividades e ações que envolvam captação e transplante de órgãos e tecidos no âmbito estadual, incluindo o gerenciamento da lista de espera. ${ }^{6}$

A partir de 2001, mediante determinação da Portaria GM/MS n 905/2000, foram desenvolvidas no Brasil as Comissões Intra-Hospitalares de Doação de Órgãos e Tecidos para Transplante (CIHDOTT). Ainda, conforme a Portaria $n^{\circ} 1.752$, de 2005, do Ministério da Saúde, todos os hospitais do país, com número de leitos superior a 80 , devem possuir uma comissão, sendo ela responsável pela notificação obrigatória do potencial doador à CNCDO. ${ }^{7,8}$

Uma das finalidades dessas comissões é o diagnóstico mais precoce de morte encefálica (ME). Morte encefálica é definida no Brasil como a parada total do funcionamento das atividades do tronco e hemisférios cerebrais. ${ }^{9}$ Para confirmação da $\mathrm{ME}$, é necessário, inicialmente, identificar a causa do coma, certificar-se de que o paciente não esteja recebendo drogas depressoras do sistema nervoso central (SNC) e não apresente alterações como hipotermia, hipertensão ou hipotensão arterial. O diagnóstico requer conhecimento científico da equipe médica e da Enfermagem para identificar o potencial doador e garantir a viabilidade dos órgãos. ${ }^{10}$

No Brasil, entre janeiro e setembro de 2016, o número na lista de espera por um transplante chegou a 33.622 pessoas, entre adultos e crianças. Já, em Santa Catarina, 359 pessoas aguardavam naquele período por um órgão. ${ }^{6}$

Diante desses números tão expressivos da insuficiente abordagem do tema na academia e do contato com profissionais da área, envolvidos no processo de doação e transplantes de órgãos, o tema passou a ser de interesse para as pesquisadoras.

\section{OBJETIVO}

Caracterizar o conhecimento dos acadêmicos de um curso de graduação de Enfermagem de Joinville/SC sobre doação de órgãos e tecidos para transplantes e, especificamente, comparar o conhecimento entre acadêmicos do primeiro ao quinto ano do curso sobre o tema, analisar a importância da doação de órgãos e tecidos para transplantes e levantar o perfil do potencial doador entre a população estudada.

\section{MÉTODOS}

Pesquisa qualitativa de caráter descritivo, com 152 acadêmicos matriculados do primeiro ao quinto ano, no período matutino, em um curso de graduação em Enfermagem de Joinville. A pesquisa foi aprovada pelo Comitê de Ética em Pesquisa (CEP), Instituto Superior e Centro Educacional Bom Jesus e lelusc, número do parecer: 2.046.967, com autorização prévia da instituição e posterior assinatura do TCLE pelos participantes da pesquisa.

A coleta de dados foi realizada em março de 2017. A escolha por esse período deveu-se a questões logísticas. Participaram estudantes que estavam presentes em sala de aula e que aceitaram colaborar. Foram excluídos menores de 18 anos, acadêmicos matriculados em outros períodos e os que não estavam presentes no momento da coleta.

A pesquisa foi apresentada com os objetivos e esclarecimentos necessários; na sequência, foi solicitada a assinatura do termo de conhecimento livre e esclarecido (TCLE), conforme disposto na Resolução $466 / 12$. Em cada sala de aula, as pesquisadoras solicitaram permissão do docente para explicar a pesquisa e levantar as informações necessárias para o estudo, recolhendo em seguida o instrumento.

Os participantes responderam a um questionário com perguntas abertas e fechadas, contendo dados socioeconômicos e questões de múltipla escolha sobre doação de órgãos e tecidos para transplante, contendo, intencionalmente, itens não verdadeiros. Opinaram, também, sobre o processo de transplante e doação de órgãos.

Após recolhidos, os questionários foram organizados por ano de matrícula e numerados sequencialmente, conforme a fase de matrícula. Para preservar o anonimato dos participantes, optou-se por identificálos por nomes bíblicos. O instrumento de coleta passou por pré-teste e falhas foram corrigidas para evitar viés. Perguntas descritivas foram submetidas à análise temática de Minayo, classificadas em três etapas: pré-análise, exploração do material e tratamento dos resultados obtidos, e interpretação. ${ }^{9}$

Todas as respostas foram transcritas em planilhas organizadas pelas pesquisadoras conforme o ano do curso acadêmico, e posteriormente foi realizada leitura intensa das informações. 


\section{RESULTADOS}

\section{A. Caracterização dos Respondentes}

Os participantes desta pesquisa estão caracterizados na tabela 1.

Tabela 1. Distribuição dos estudantes, conforme o ano matriculado e sexo. Joinville, SC- 2017.

\begin{tabular}{|c|c|c|c|c|c|c|c|c|c|c|c|c|}
\hline \multirow{2}{*}{$\begin{array}{l}\text { Ano } \\
\text { Acadêmico }\end{array}$} & \multicolumn{2}{|c|}{10 ano } & \multicolumn{2}{|c|}{$2^{\circ}$ ano } & \multicolumn{2}{|c|}{ 3ㅇ ano } & \multicolumn{2}{|c|}{$4^{\circ}$ ano } & \multicolumn{2}{|c|}{ 50 ano } & \multicolumn{2}{|c|}{ Total } \\
\hline & $\mathrm{N}$ & $\%$ & $N$ & $\%$ & $\mathrm{~N}$ & $\%$ & $N$ & $\%$ & $\mathrm{~N}$ & $\%$ & $N$ & $\%$ \\
\hline$M$ & 4 & 15 & 3 & 9 & 4 & 11 & 4 & 13 & 2 & 8 & 17 & 11 \\
\hline $\mathrm{F}$ & 22 & 85 & 31 & 91 & 32 & 89 & 26 & 87 & 24 & 92 & 135 & 89 \\
\hline Total & 26 & 100 & 34 & 100 & 36 & 100 & 30 & 100 & 26 & 100 & 152 & 100 \\
\hline
\end{tabular}

Legenda: $M=$ Masculino,$F=$ Feminino

Dos 152 participantes, houve predominância do sexo feminino; prevaleceu a profissão na área da saúde e estudantes. A maioria tem vínculo empregatício, correspondendo respectivamente a: quinto ano, 23; quarto, 24; segundo, 20; terceiro, 19 e primeiro, 13. Do total de convidados, 99 têm vínculo empregatício remunerado.

A religião católica foi a mais citada, seguida da evangélica. No terceiro, quarto e quinto anos, poucos auto identificaram-se como espíritas; no segundo e terceiro anos um pequeno número declarou-se ateu. Dos participantes, 80 não têm familiares que trabalham na área da saúde.

Em relação à renda familiar, 71 deles recebem de três a cinco salários mínimos.

\section{B. Processo de captação, doação e transplantes de órgãos e tecidos.}

$\mathrm{Na}$ identificação do que sabem os estudantes de Enfermagem sobre o processo de captação, doação e transplante de órgãos, as respostas permitiram verificar que a morte encefálica é: a perda irreversível das funções cerebrais, para os alunos do primeiro ao quinto ano, correspondendo, sequencialmente, a: 23 ; 30; 35; 30 e 26 alunos.

No primeiro ano, dois responderam que a ME é o estado de coma induzido e um deixou a questão em branco. No segundo, dois participantes assinalaram a alternativa de coma induzido para o estado de ME, um deixou a questão em branco e um declarou não saber. No terceiro ano, um respondeu que é o estado de coma induzido. Já no quarto e quinto anos, todos os participantes assinalaram a ME como perda irreversível das funções cerebrais.
$\mathrm{Na}$ tabela 2, estão apresentados acertos e erros com relação aos órgãos e transplantes, conforme a resposta dos participantes às questões de múltipla escolha. Verifica-se que o terceiro ano teve o maior número de acertos, correspondendo a 287; destes, a resposta mais evidente foi córneas e rins, com 36.

Tabela 2. Visão dos acadêmicos de Enfermagem sobre órgãos e tecidos que podem ser transplantados em uma faculdade de Joinville/SC, 2017/2.

\begin{tabular}{|c|c|c|c|c|c|c|c|c|c|c|c|c|}
\hline $\begin{array}{l}\text { Ano } \\
\text { Acadêmico }\end{array}$ & \multicolumn{2}{|c|}{10 ano } & \multicolumn{2}{|c|}{20 ano } & \multicolumn{2}{|c|}{ 3ㅇ ano } & \multicolumn{2}{|c|}{ 40 ano } & \multicolumn{2}{|c|}{50 ano } & \multicolumn{2}{|c|}{ Total } \\
\hline ÓRGÃOS & A & $E$ & A & $E$ & A & $E$ & A & $E$ & A & $E$ & A & E \\
\hline $\begin{array}{l}\text { Medula } \\
\text { óssea }\end{array}$ & 20 & 6 & 29 & 5 & 30 & 6 & 24 & 6 & 25 & 1 & 128 & 24 \\
\hline Cérebro & 26 & 0 & 34 & 0 & 36 & 0 & 30 & 0 & 26 & 0 & 152 & 0 \\
\hline Córneas & 22 & 4 & 33 & 1 & 36 & 0 & 29 & 1 & 26 & 0 & 146 & 6 \\
\hline Fígado & 21 & 4 & 32 & 2 & 34 & 2 & 28 & 2 & 22 & 4 & 137 & 14 \\
\hline Pulmão & 17 & 9 & 25 & 9 & 30 & 6 & 22 & 8 & 19 & 7 & 123 & 39 \\
\hline Sangue & 15 & 12 & 29 & 5 & 24 & 12 & 16 & 14 & 9 & 17 & 93 & 60 \\
\hline Ossos & 9 & 17 & 9 & 25 & 18 & 18 & 6 & 24 & 17 & 9 & 59 & 93 \\
\hline Rins & 25 & 1 & 33 & 1 & 36 & 0 & 30 & 0 & 25 & 1 & 149 & 3 \\
\hline Pâncreas & 11 & 15 & 16 & 18 & 23 & 13 & 17 & 13 & 17 & 9 & 84 & 61 \\
\hline $\begin{array}{l}\text { Válvulas } \\
\text { cardíacas }\end{array}$ & 11 & 15 & 16 & 18 & 20 & 16 & 11 & 19 & 16 & 10 & 74 & 78 \\
\hline Útero & 0 & 2 & 0 & 0 & 0 & 18 & 0 & 1 & 0 & 0 & 0 & 21 \\
\hline Total & 177 & 85 & 256 & 84 & 287 & 73 & 213 & 87 & 202 & 58 & 1145 & 399 \\
\hline
\end{tabular}

Legenda: $A=$ Acertos; $E=$ Erros

Quanto aos órgãos e tecidos que podem ser doados após a parada cardíaca irreversível, as informações estão distribuídas conforme mostra a tabela 3 . O quinto ano destacou-se, alcançando o maior número de acertos em relação à doação das córneas e dos ossos. Verifica-se que em todos os anos, os alunos têm conhecimento de que as córneas podem ser doadas após parada cardíaca irreversível, apresentando o menor número de erros em relação aos outros órgãos.

A resposta quanto à viabilidade dos órgãos após explante está disposta na tabela 4.

Quanto à preservação extracorpórea dos órgãos para transplante, observou-se que ainda há dificuldade em identificar o tempo de viabilidade após o explante. Dentre as patologias que excluem o potencial doador, conforme os respondentes do primeiro ano foram 68 acertos; do segundo e do quarto, 88; 101 do terceiro e 70 do quinto. O terceiro ano destaca-se com o maior número de acertos; do quinto ano todos assinalaram que o HIV exclui o potencial doador. 
Tabela 3. Número de acertos e erros dos acadêmicos do curso de graduação de enfermagem relacionados a órgãos e tecidos que podem ser doados após a parada cardíaca irreversível. Joinville/ SC, 2017/2

\begin{tabular}{lcccccccccccccc}
\hline $\begin{array}{l}\text { Ano } \\
\text { Acadêmico }\end{array}$ & 10 ano & 20 ano & 30 ano & 40 ano & 50 ano & \multicolumn{2}{c}{ Total } \\
\hline ÓRGÃos & A & E & A & E & A & E & A & E & A & E & A & E \\
Córneas & 21 & 5 & 25 & 9 & 34 & 2 & 28 & 2 & 25 & 1 & 133 & 19 \\
Coração & 23 & 3 & 29 & 5 & 32 & 2 & 27 & 3 & 21 & 5 & 132 & 18 \\
Pulmão & 18 & 8 & 24 & 10 & 31 & 5 & 21 & 9 & 17 & 9 & 111 & 41 \\
Rins & 11 & 15 & 14 & 20 & 18 & 18 & 1 & 19 & 20 & 16 & 64 & 88 \\
Fígado & 13 & 13 & 17 & 17 & 19 & 17 & 14 & 16 & 13 & 13 & 76 & 76 \\
Pâncreas & 19 & 7 & 26 & 8 & 26 & 10 & 20 & 10 & 18 & 8 & 109 & 43 \\
Ossos & 9 & 17 & 6 & 28 & 13 & 23 & 2 & 28 & 14 & 12 & 44 & 108 \\
\hline Total & 114 & 68 & 41 & 97 & 173 & 77 & 113 & 87 & 128 & 64 & 669 & 393 \\
\hline
\end{tabular}

Legenda: $A=$ Acertos; $E=$ Erros

Tabela 4. Tempo de viabilidade extracorpórea dos órgãos conforme resposta dos acadêmicos. Joinville SC/2017.

\begin{tabular}{lcccccccccccc}
\hline $\begin{array}{l}\text { Ano } \\
\text { Acadêmico }\end{array}$ & 10 ano & 20 ano & \multicolumn{2}{c}{ 30 ano } & 40 ano & 50 ano & \multicolumn{2}{c}{ Total } \\
\hline ÓRGÃos & A & E & A & E & A & E & A & E & A & E & A & E \\
Córneas & 6 & 7 & 6 & 6 & 8 & 2 & 28 & 2 & 25 & 1 & 133 & 19 \\
Coração & 2 & 6 & 5 & 3 & 9 & 3 & 34 & 6 & 1 & 10 & 22 & 39 \\
Pulmão & 11 & 25 & 12 & 2 & 11 & 3 & 6 & 3 & 10 & 1 & 50 & 10 \\
Rins & 11 & 1 & 7 & 6 & 7 & 6 & 7 & 2 & 6 & 5 & 38 & 20 \\
Fígado & 2 & 9 & 3 & 11 & 8 & 5 & 3 & 6 & 5 & 6 & 21 & 37 \\
Pâncreas & 7 & 4 & 5 & 6 & 7 & 5 & 3 & 6 & 9 & 2 & 31 & 23 \\
Ossos & 1 & 10 & 9 & 1 & 4 & 9 & 1 & 8 & 8 & 3 & 23 & 31 \\
\hline Total & 40 & 44 & 54 & 44 & 49 & 39 & 28 & 41 & 48 & 30 & 219 & 185 \\
\hline
\end{tabular}

Legenda: $A=$ Acertos; $E=$ Erros

\section{Opinião dos acadêmicos sobre transplante de tecidos e órgãos}

$\mathrm{Na}$ análise da importância do tema no meio acadêmico, a partir das respostas descritivas, emergiram as seguintes categorias: reflexão favorável sobre o processo de doação de órgãos e tecidos para transplantes, o processo de doação de órgãos e tecidos como um ato solidário e avanço tecnológico capaz de salvar vidas, articulação dos serviços informativos para esclarecimento da população e formação do enfermeiro como estratégia para ampliar o processo de transplante e doação, as quais são apresentadas na sequência.

\section{Refletindo sobre o processo de doação de órgãos e tecidos para transplantes de modo favorável}

Ao explorar as respostas, os acadêmicos, predominantemente, declararam-se favoráveis à doação e veem a não doação como um desperdício dos órgãos que poderiam curar ou tratar outras pessoas.

O conhecimento da família sobre o desejo do potencial doador é um fator que influencia na decisão final, já que é um momento delicado e de fragilidade. A doação aparece como uma maneira de proporcionar o enfrentamento do luto, garantindo que o órgão do seu ente querido melhore a qualidade de vida de outras pessoas. São falas que destacam essas ideias:

\begin{abstract}
"Acho importante a conscientização, os familiares devem estar cientes da vontade do indivíduo, caso haja a possibilidade de ser doador." (Josué)
\end{abstract}

\begin{abstract}
"Eu penso que isso é essencial, uma atitude muito respeitável, que irá fazer a diferença para outras pessoas e toda uma família. Acho a atitude correta a ser feita, em vez de deixar os órgãos entrar em falência e se decomporem sem utilidade alguma." (Juízes)
\end{abstract}

"Que é um ato muito importante e que deve ser abordado mais frequentemente e abertamente. Sabemos que no meio disto temos que respeitar crenças e religião, mas se as pessoas se colocassem no lugar das que estão esperando um órgão, os papéis inverter-se-iam. Meu pai foi doador de órgãos após a morte encefálica e, apesar de toda dor e luto, saber que ele estaria ajudando outras pessoas a viverem ou melhorarem sua qualidade de vida confortou-nos naquele momento difícil. É um assunto que deve ser abordado com mais naturalidade." (Rute)

\section{O processo de doação de órgãos e tecidos como um ato solidário e avanço tecnológico capaz de salvar vidas}

Por meio das falas, percebe-se que os acadêmicos de Enfermagem entendem que a doação de órgãos e tecidos para transplante é possível graças ao avanço científico da Medicina. Junto a isso, a maioria descreve a doação como um ato de amor ao próximo e de solidariedade:

"É uma maneira de salvar vidas e fazer o bem. Método revolucionário, que possibilita grandes avanços na medicina." (Reis)

\footnotetext{
"Em minha opinião a doação de órgãos e tecidos é uma ação muito bonita, pois está ajudando a quem precisa ou a quem ainda tem uma chance para viver." (Ester)

"Sou totalmente a favor, pois se o avanço da Medicina foi capaz de proporcionar a continuidade da vida de forma "saudável" a uma pessoa que corre risco de morte, por que não utilizar esse benefício, que salva vidas?" (Jó)
} 


\section{A articulação dos serviços informativos para esclarecimento da população}

Parte dos participantes demonstra preocupação com a falta de conhecimento da população de modo geral, e acredita ser um dos fatores de maior relevância no que diz respeito à negação por parte da família. Descreve a importância de intensificar o tema por parte do poder público e utilizar a mídia na propagação de mais informações. Atribui a essas ações a possibilidade de aumentar a captação de novos doadores e diminuir o tempo de permanência das pessoas na lista de espera.

Nas palavras dos participantes:

\begin{abstract}
"Acho que deveria ser divulgado pela mídia, para que haja conscientização da população quanto a esse assunto, e para que as pessoas tenham clareza de que se trata de mais vidas a serem salvas." (Salmos)

"Acho que é uma atitude excepcional e de muita importância, pois salva muitas vidas. Deveria haver mais informação para a população geral sobre a importância." (Isaías)

"Sou a favor, espero poder doar meus órgãos. Porém, precisamos trabalhar mais com a população sobre o assunto, pois a resistência à doação ainda é bem grande." (Ezequiel)
\end{abstract}

\section{A formação do enfermeiro como estratégia para ampliar o processo de transplante e doação}

Pouco conhecimento científico, no que se refere à doação de órgãos e tecidos para transplante é uma afirmativa descrita pelos participantes, os quais destacam que o assunto deveria ser abordado com ênfase nas faculdades e universidades. Também ressaltam a relevância de o enfermeiro ter conhecimento sobre o tema para realizar a abordagem adequada ao familiar, já que muitas vezes esse é o primeiro profissional a ter contato com a família do potencial doador:

"Importante, porém pouco explorado na universidade, nos locais de saúde e nas mídias." (Daniel)

"Acho necessário e deveria ser um tema mais abordado nas instituições de ensino em cursos da saúde, pois muitas vezes somos o primeiro profissional a ter contato com a família no momento dessa decisão." (Oseias)

"A doação é uma boa opção para salvar vidas, $e$ nós, como enfermeiros que visamos ao bem-estar do paciente, temos que nos atualizar para as novas descobertas desse assunto." (Joel)

"Acredito ser uma atitude importante para a sociedade quando diz respeito a salvar vidas. Porém, poderia ser um tema mais esclarecido para a sociedade e mais estudado pelos acadêmicos." (Jonas)
"Não sei muito a respeito do assunto porque nunca busquei informações. É muito relevante e necessário ter conhecimento sobre doação de órgãos e tecidos para transplantes." (Miqueias)

\section{DISCUSSÃO}

Para Morato (2009), ${ }^{11}$ a morte encefálica representa o estado clínico irreversível em que as funções cerebrais e do tronco encefálico estão irremediavelmente comprometidas. Maia e Amorim (2009), ${ }^{9}$ em pesquisa com 531 acadêmicos de Enfermagem ( $2^{\circ}$ ao $8^{a}$ período) e Medicina ( $1^{\mathrm{a}}$ ao $9^{\circ}$ período), concluíram que eles definiram corretamente ME.

Verificou-se que o resultado encontrado neste estudo acompanha essa literatura. Notou-se ainda que os acertos aumentaram, conforme a progressão ao longo da estrutura curricular.

No Brasil, os órgãos e tecidos que podem ser transplantados, atualmente, são: coração, fígado, pâncreas, pulmões, rins, córneas, válvulas cardíacas, vasos sanguíneos e ossos. ${ }^{2}$ Verificou-se que os órgãos mais comumente transplantados são de conhecimento da maioria dos participantes, porém, os transplantes de ossos, pâncreas e válvulas cardíacas mostraram-se pouco populares no meio acadêmico.

Chamou atenção que o sangue não tivesse sido percebido como um tecido passível de doação por grande parte dos acadêmicos do quinto ano do curso. Acredita-se que isso esteja relacionado ao fato de que o sangue e a medula óssea são obtidos a partir de doação intervivos. ${ }^{2}$ Entende-se que a doação de sangue é corriqueira, portanto, esse erro pode estar associado à interpretação da palavra tecido.

Em se tratando da viabilidade dos órgãos e tecidos após a parada cardíaca, é possível afirmar que apenas as córneas e os ossos mantêm sua viabilidade para transplante após a parada cardíaca irreversível. O tempo máximo de preservação extracorpórea das córneas corresponde a sete dias, e dos ossos, cinco anos. ${ }^{2}$ Ao analisarmos as respostas, obtivemos 185 respostas incorretas e 84 declararam desconhecimento. As respostas evidenciaram que há dificuldade em reconhecer o tempo de viabilidade dos órgãos.

Maiores acertos nessa temática foram apontados por Cicolo, Roza e Schirmer (2010), ${ }^{4}$ em pesquisas desenvolvidas em sua maioria por enfermeiros assistenciais, o que explica que é a vivência profissional e não a formação acadêmica que permite aprofundamentos específicos. Justificam ainda as autoras que isso pode relacionar-se ao reduzido número de cursos lato sensu e ou stricto sensu somados à falta de abordagem durante a graduação. 
Não devem ser consideradas doadoras pessoas com patologias que podem ser transmitidas a partir de transplantes e também sepse ou insuficiência de múltiplos órgãos e sistemas. Assim, Doença de Chagas, HIV, hepatites B e C, neoplasias malignas, exceto tumor limitado ao SNC restringem a doação de órgãos. ${ }^{2}$

Nos resultados desta pesquisa, um pequeno grupo do primeiro ao quarto ano apontou pessoas com HIV como possíveis doadores. Do primeiro ao quinto ano responderam como possíveis doadoras pessoas com hepatites B, C e leucemia. As respostas mostraram que mesmo temas abordados cotidianamente na formação ,como doenças transmissíveis, não são lembrados como fatores que excluem o potencial doador.

Com relação às categorias deste estudo, concorda-se que, de fato, a tecnologia trouxe benefícios para o setor da saúde. Lorenzetti, Trindade e Pires et al. (2012) ${ }^{13}$ destacam a importância desse avanço quando referem que ciência e tecnologia são ferramentas importantes para o indivíduo, seja para o tratamento de patologias, para um momento civilizatório de paz ou permitindo vida digna e de qualidade. Para Império (2007), ${ }^{14}$ os avanços tecnológicos, farmacológicos e imunológicos são importantes e repercutem na qualidade e viabilidade dos órgãos, assim como relatado nas falas dos participantes.

Segundo Moraes e Massarollo (2009), ${ }^{15}$ os familiares são responsáveis pela decisão da doação. Para apoiálos, são necessárias informações sobre o quadro clínico de forma clara, para não gerar dúvidas e minimizar o desconforto, fatores esses que podem resultar em uma resposta negativa à doação. Para Ladessa, Silva e Oliveira (2015), ${ }^{16}$ o momento de despedida do ente querido inicia-se durante o protocolo de ME, o que favorece maior suporte para enfrentar o luto.

Embora nesta pesquisa os participantes destaquem a necessidade de serviços informativos que estejam a favor da população, o estudo de Moraes e Moraes (2012) ${ }^{17}$ diz que a falta de conhecimento e informações dos profissionais pode gerar interpretações erradas sobre a temática, destacando que as informações recebidas em massa por meio da mídia não são suficientes para conscientizar a população, afirmando ainda a necessidade de o governo investir em atividades educativas ao invés de informativas. Apesar desse posicionamento dos autores, os acadêmicos desta pesquisa acreditam na suficiência das informações veiculadas na imprensa.
Segundo estudo de Moura, Souza e Ribeiro (2011), ${ }^{18}$ há falta de conhecimento científico sobre o assunto por parte dos acadêmicos de Enfermagem, sendo imprescindível sua abordagem durante a graduação. O enfermeiro exerce papel fundamental na equipe de doação e captação, sendo responsável pelo planejamento, execução e coordenação do processo. ${ }^{19}$ As falas dos acadêmicos deste estudo vêm ao encontro da literatura referida.

\section{CONCLUSÃO}

Os acadêmicos possuem conhecimento sobre o tema, identificando a viabilidade dos órgãos, aqueles que podem ser transplantados e as doenças que restringem a doação, entre outras informações.

Observa-se que o conhecimento avança conforme a fase acadêmica, visto que permite vivenciar situações iguais ou semelhantes nos diversos campos de ensino teórico, prático e nos estágios oferecidos. No entanto, percebeu-se a necessidade da temática na academia, o que pode contribuir para a formação do profissional que se mantém à frente no trabalho desenvolvido pelas comissões de transplante de órgãos. Ademais, o enfermeiro é membro fundamental na equipe para manutenção do potencial doador, abordagem à família, capacitação profissional e educação com a população.

Acredita-se que algumas ações contribuam para a formação durante a graduação em Enfermagem; dentre elas, destaca-se a oferta de disciplina optativa.

Por intermédio deste estudo, pode-se afirmar que o potencial doador no círculo acadêmico da graduação é jovem, do sexo feminino, o que condiz com a feminilização da enfermagem.

Considerando esse contexto, observou-se que estudos podem incentivar acadêmicos a ampliar seus conhecimentos, evidenciando a importância e a real necessidade do saber dos profissionais enfermeiros em relação à doação de órgãos e tecidos para transplante.

No geral, a doação é importante para salvar vidas e melhorar a qualidade dos que esperam pelo tão sonhado transplante.

Por fim, como limites desta pesquisa, cabe destacar a coleta de dados durante o período de aulas, o que pode ter influenciado no tempo e na qualidade das respostas. 


\section{ABSTRACT}

In Brazil the need for transplants has been growing and nurses are responsible by several actions in the different stages of this process; along the training, it is relevant to be aware of the aspects involved. Purpose: to characterize the knowledge of the academic nursing from a undergraduate course in Joinville/SC on organ and tissue donation for transplants. Methods: qualitative descriptive research conducted with 152 participants enrolled from the first to the fifth year of the course. Data collected by means of questionnaires with open and closed questions answered in their own handwriting during the period of classes. Content analysis was performed in the thematic analysis modality. Results: the following categories emerged from the interpretation: reflection on the organ and tissue donation process for transplants in a favorable way; the process of organ and tissue donation as a life-saving act of solidarity and technological advancement; the information services articulation to clarify the population; training of nurses as a strategy to expand the transplantation and donation process. Conclusion: it was observed that the academics are aware on the subject, identifying the organ feasibility; which ones can be transplanted; diseases restricting the donation, among other information. In general, it is deemed necessary to approach the theme along the training. It is supposed that courses might develop educational tools to address the issue.

Keywords: Obtaining Organs; Organ Transplantation; Students, Nursing.

\section{REFERÊNCIAS}

1. Dalbem GG, Caregnato RCA. Doação de órgãos e tecidos para transplante: recusa das famílias. Texto \& contexto enferm. 2010;19(4):728-35.

2. Repka JCR, Mozachi N, Souza VHS, Contieri FLC. Transplantes. In: Souza VHS, MOZACHI N. O hospital: manual do ambiente hospitalar. $3^{\mathrm{a}}$ ed. Curitiba: Manual Real; 2009;382-96.

3. Regulamenta a Lei $n^{\circ} 9.434$, que dispõe sobre a remoção de órgãos, tecidos e partes do corpo humano para fim de transplante e tratamento, e dá outras providências. Decreto $n^{\circ}$ 2.268. Diário Oficial da União; Seção 1; página 13739. (01 jul.1997).4. Cicolo EA, Roza BA, Schirmer J. Doação e transplantes de órgãos: produção científica da enfermagem brasileira. Rev. bras. enferm. 2010;63(2):274-8.

5. Pereira AW, Fernandes RC, Soler VW. Diretrizes básicas para captação e retirada de múltiplos órgãos e tecidos da associação brasileira de transplante de órgãos. 2009.

6. Secretaria Estadual da Saúde Santa Catarina. Histórico. [Acesso em: 08 nov. 2016]. Disponível em: http://sctransplantes.saude. sc.gov.br/index.php/a-instituicao-vertical/historico.

7. Determina a constituição de Comissão Intra-Hospitalar de Doação de Órgãos e Tecidos para Transplante em todos os hospitais públicos, privados e filantrópicos com mais de 80 leitos. Portaria $n^{\circ} 1752$; Ministério da Saúde do Brasil. Diário Oficial da União; seção 1:54. (27 set. 2005).

8. Critérios para a caracterização de morte encefálica. Resolução n. 1.480; Conselho Federal de Medicina. Diário Oficial da União p. 18.227. (21.ago.1997).

9. Maia BO, Amorin JS. Morte encefálica: conhecimento de acadêmicos de enfermagem e medicina. J Bras Transpl [periódico na internet]. 2009;12(2):1088-91. Disponível em: http://www.abto.org.br/abtov03/Upload/file/JBT/2009/2. pdf\#page=8.
10. Minayo MCS. Contradições e consensos na combinação de métodos quantitativos e qualitativos: discussão crítica sobre métodos quantitativos e qualitativos. In: Minayo MCS. O desafio do conhecimento: pesquisa qualitativa em saúde. $13^{a}$ ed. São Paulo: Hucitec; 2013. p. 54-80.

11. Morato EG. Morte encefálica: conceitos essenciais, diagnóstico e atualização. Rev. méd. Minas Gerais. 2009;19(3):185-276.

12. Souza AB, Gomes EB, Leandro MLS. Fatores contribuintes para a adesão à doação de sangue e medula óssea. Cad. Cult. Ciênc. 2008;2(1):7-14.

13. Lorenzetti J, Trindade LL, Pires DEP, Ramos FRS. Tecnologia, inovação tecnológica e saúde: uma reflexão necessária. Texto \& contexto enferm. 2012; 21(2):432-9.

14. D’império F. Morte encefálica, cuidados ao doador de órgãos e transplante de pulmão. Rev. bras. ter. intensiva. 2007;19(1):7484.

15. Moraes EL, Massarollo MCKB. Recusa de doação de órgãos e tecidos para transplante relatados por familiares de potenciais doadores. Acta Paul. Enferm. 2009;22 (2):131-5.

16. Ladessa LECL, Silva SC, Oliveira PC. Reflexões sobre o trabalho do psicólogo no processo de doação de órgãos. In: Jornada de Psicologia no Hospital Municipal do Campo Limpo: Anais da V Jornada de Psicologia no Hospital Municipal do Campo Limpo; 09 out 2014; São Paulo. São Paulo: Blucher Medical Proceedings; 2015; 22-5.

17. Moraes TR, Moraes MR. Doação de órgãos: é preciso educar para avançar. Saúde debate. 2012;36(95):633-9.

18. Moura KHM, Souza TF, Ribeiro GTF. Percepção dos acadêmicos de enfermagem sobre a doação de órgãos e tecidos. Rev. enferm. UFPE [Periódico on line] 2011[Acesso em 10 abr. 2016];24(2):1353-61. Disponível em: https://periodicos. ufpe.br

19. Batista, ACV, Junior OLS, Canova JCM. Atuação do enfermeiro no processo de doação de órgãos e tecidos para transplante. J Bras Transpl. 2012;15(4):1709-14. 